\title{
Bargaining and Conflict with Up-front Investments: How Power Asymmetries Matter
}

\author{
Zachary Schaller and Stergios Skaperdas*
}

June 21, 2019

\begin{abstract}
We examine settings - such as litigation, labor relations, or arming and war - in which players first make non-contractible up-front investments to improve their bargaining position and gain advantage for possible future conflict. Bargaining is efficient ex post, but we show that a player may prefer Conflict ex ante if there are sufficient asymmetries in strength. There are two sources of this finding. First, up-front investments are more dissimilar between players under Conflict, and they are lower than under Bargaining when one player is much stronger than the other. Second, the probability of the stronger player winning in Conflict is higher than the share received under Nash bargaining. We thus provide a rationale for conflict to occur under complete information that does not depend on long-term commitment problems. Greater balance in institutional support for different sides is more likely to maintain peace and settlements.
\end{abstract}

*Department of Economics, University of California, Irvine. zschalle@uci.edu, sskaperd@uci.edu. We would like to thank Marek Kaminski and participants at the 2019 Public Choice Society Meeting for useful comments; also, Jean-Paul Carvalho and participants in the Institute for Mathematical Behavioral Sciences Workshop, Contests: Theory and Evidence 2018 Conference, and the 2018 Southern Economics Association Meeting. 
Keywords: Power asymmetries, war, litigation, contests JEL codes: C70, D74, J53, K41

\section{Introduction}

Why does conflict occur? At its worst it is catastrophic; at its best, harmful and wasteful. Economists and other social scientists posited first asymmetric information as a cause of conflict. A second set of causes that has been more recently examined involve incomplete contracting and the inability of adversaries to commit. ${ }^{1}$ Within the broad category of incomplete contracting - the inability of adversaries to write long-term binding contracts - we show how large asymmetries in power could induce conflict.

Power asymmetries have been invoked as a cause of conflict in many settings. Wrangham and Glowacki (2012) present evidence that groups of chimpanzees and groups of human hunter-gatherers both follow the same strategy: Attack only when you have overwhelming superiority over your adversary. Considerably more research - and controversy - surrounds the issue of power asymmetry in political science and international relations. Depending on the context, great power asymmetry can induce war or facilitate peace (see Wagner, 1994, for a synthetic view). The experience of U.S. foreign wars over the past forty years is consistent with wars taking place when there is overwhelming power asymmetry. All the wars in which the U.S. has been involved, at least since the invasion of Grenada in 1983, were against vastly inferior adversaries, militarily speaking. Such power asymmetry has been manifest in practice and even codified in semi-official policy such as the "Powell doctrine," named after former U.S. Secretary of State Colin Powell (see O'Sullivan, 2009). Of course, we neither claim that power asymmetries always lead to war nor that the particular mechanism we examine is the only one that may lead to war in the presence of asymmetries. Before we discuss the mechanism that we analyze, we first present the settings that we examine.

\footnotetext{
${ }^{1}$ An early form of the asymmetric information argument can be found in Wittman (1979) in the context of wars that was subsequently extensively elaborated in gametheoretic models during the 1980s. Cramton and Tracy (2003) present the argument in the context of industrial conflict. Different forms of the inability to commit argument have been advanced by Garfinkel and Skaperdas (2000), Robson and Skaperdas (2008), Bevia and Corchon (2010), McBride and Skaperdas (2014), Kimbrough et al. (2015), and Garfinkel and Syropoulos (2018). Smith et al. (2014) show how conflict is less likely when the costs of conflict are endogenous to arming. Fearon (1995) and Skaperdas (2006) present overviews of how conflict could come about.
} 
We consider economic and political environments in which the set of bargaining alternatives - the utility possibilities set - and the disagreement point are endogenous in the following sense: ${ }^{2}$ Players first make up-front investments that determine both the range of alternatives available and each player's disagreement utility through probabilities of winning and losing a contest or conflict. Then, in the case of conflict, variable resources have to be expended to determine the probabilities of winning. We are thinking of the up-front investments as "capital" and the variable resources as "labor," combining through a production function that determines each player's total effort and chance of winning a contest. Both of the inputs are noncontractible. Conditional on having the opportunity to bargain, the players would have no incentive to choose their disagreement utility and enter into conflict. Yet, entering into conflict might be ex ante preferable by at least one of the players, causing them to commit to conflict. Our functional assumptions have been axiomatized by Rai and Sarin (2009) and Arbatskaya and Mialon (2010). Münster (2007) had earlier provided an analysis of such contests for all-pay auctions whereas Arbatskaya and Mialon (2012) analyzed a version of our Conflict game but without Bargaining.

Examples of the settings that our framework fits include the following:

- Military expenditures and wars. States and other parties to conflict invest in hardware, military personnel, and organizational infrastructure regardless of whether war is coming or not. If it does come, additional resources are deployed, therefore making war costly (beyond destruction and additional costs).

- Litigation and going to court. In such settings, the up-front investments cover the hiring of lawyers and expenditures on exploration and discovery; the variable inputs would include the extra expenses of going to court. We examine the conditions under which going to court might be preferable to settling out of court.

- Interactions of unions and firms. Unions expend resources on organizational infrastructure, building solidarity among their members, publi-

\footnotetext{
${ }^{2}$ Nash (1950) defined the bargaining problem in terms of two objects: The set of alternatives or utility possibilities set for the two players and the disagreement or threat point. These two objects can be derived in any economic environment that involves production, trade, even conflict, in either deterministic or stochastic environments. The beauty of Nash's approach (initially perhaps not sufficiently appreciated) was distilling such a variety of economic contexts in these two objects, as well as defining his Nash bargaining solution within the same paper. Much research on bargaining has concentrated on defining other bargaining solutions to that of Nash as well as developing non-cooperative bargaining games.
} 
cizing their perspective to the press and the wider public, and building contingency funds in case of a strike. Firms hire lawyers and other experts to help handle relations with unions and the press and, in anticipation of work stoppage, they may build inventories above normal levels. These are representative of up-front investments meant to improve the respective side's bargaining position even if conflict is not expected.

- Lobbying and policy formation. Lobbying firms and think tanks invest in office space, researchers, lawyers, secretaries, public relations specialists, and, of course, lobbyists. This infrastructure behind the lobbyists themselves can be considered up-front investment that is used to promote different policies and bills. Such up-front investment is usually deployed on a range of policies, but the issue of whether to go all out and try to win or compromise with other interest groups is a choice they face.

With such settings in mind, we examine and compare the equilibria of two games, a Conflict game and a Bargaining game. In the Conflict game, each player first makes up-front investments that are mutually observed before conflict ensues. The two sides then devote additional variable resources to conflict. Under the Bargaining game, the two players make up-front investments and then negotiate to divide the prize. They do so, however, under the threat of conflict whereby the disagreement payoffs are determined by the variable resource choices under the subgame perfect equilibrium of the Conflict game. No conflict actually takes place in the Bargaining game, hence there are no additional resources expended beyond the up-front investments.

We find that up-front investments can differ significantly between Bargaining and Conflict, and the difference in investment levels between players is itself quite different between the two games. In particular, investments are similar between the players under Bargaining - only reflecting the ratio of player's marginal costs - but tend to differ substantially under Conflict when the players have significant differences in their underlying strength. Strength is measured conveniently by a summary index that reflects the following: differences in marginal costs of investments and variable resources, the effectiveness of one's efforts compared to that of the other player, and the relative importance of the two inputs. As will become clear in the model, the greater the difference in strength, the higher is the difference in the two player's investments but also the lower are total investments.

Partly as a result of the greater asymmetry of investments under Conflict, the probability of winning for the stronger player under Conflict is greater 
than the share the same player receives under Bargaining. Given then that the stronger player can have lower investments under Conflict and receives in expectation a bigger share of the pie, he or she would prefer Conflict to Bargaining. That occurs when there is sufficient asymmetry in strength, and up-front investments are sufficiently important to the production of effort. However, for high levels of this latter factor the weaker player receives a negative payoff under Conflict and in such a case would prefer not to participate in the game in the first place. ${ }^{3}$ There are even cases in which total equilibrium payoffs under Conflict are higher than total payoffs under Bargaining, although this is driven by the payoff of the stronger player.

For cases without high differences in strength, both players prefer Bargaining. Interestingly, it is possible to have strong participants and peaceful settlement. The key, to the extent that the context allows it, is to create balance between agents and eliminate sources of bias in the overall environment. This result is applicable to the union-management context where economists have tried for a long time to explain the occurrence of strikes. Supreme Court Justice Louis Brandeis took this view even at the height of labor unrest. He argued, "Strong, responsible unions are essential to industrial fair play. Without them the labor bargain is wholly one-sided. The parties to the labor contract must be nearly equal in strength if justice is to be worked out, and this means that the workers must be organized and that their organizations must be recognized by employers as a condition precedent to industrial peace." ${ }^{4}$ Hence it is the threat of strike and the balance of power that ironically establish conditions for harmony. To our knowledge, this is the first paper to present a conflict equilibrium as applied to labor relation under complete information without relying on complicated punishment strategies (e.g. Fernandez and Glazer, 1991). We show conditions under which work stoppage may be rational and preferred under complete information.

The possibility of power asymmetries inducing conflict has been analyzed experimentally by a number of papers, even though none of the experiments tests the particular mechanism of up-front investments that we examine here. Sieberg et al. (2013) examined an alternating-offers bargaining game in which disagreement implies that the two players have different exogenous probabilities of winning. Although conflict occurred in the experiments more than predicted by theory, greater asymmetry did not induce more conflict. Kimbrough et al. (2014) and Herbst et al. (2017) allowed possibly asymmetric probabilities of winning in conflict to be endogenously

\footnotetext{
${ }^{3}$ Contrary to typical "Tullock" contests in which equilibrium payoffs are positive regardless of the number of players (see, e,g., Konrad, 2009).

${ }^{4}$ Reported in Osmond Kessler Fraenkel, Clarence Martin Lewis, The Curse of Bigness: Miscellaneous Papers of Louis D. Brandeis (1965), p. 43.
} 
determined. Kimbrough et al. (2014) employed an ex ante random device instead of a bargaining game to resolve conflict and greater asymmetries induced some more conflict but not as much as expected theoretically. Herbst et al. (2017) allowed for exogenous divisions of the surplus (that reflects asymmetries) as well as endogenous bargaining (Nash demand game). Overall, they found power asymmetries to induce conflict only in the case of endogenous bargaining, a result they attribute to the strategic uncertainty inherent in endogenous bargaining.

After specifying the two games - Conflict and Bargaining - in the next section, we completely characterize the equilibria of each and then make comparisons between equilibrium payoffs. As a robustness check, in the subsequent section we allow for a different bargaining protocol in which one player has all the bargaining power so that they play an ultimatum game. It turns out that when the stronger player is not the proposer (the one with the bargaining power), then that player almost always prefers Conflict. Thus, any strength imbalance in Conflict, even slight, that is not reflected in the bargaining rule employed leads to Conflict.

\section{The Conflict and Bargaining Games}

Two sides, 1 and 2, have a surplus $S$ that they can either fight over or divide under the threat of a fight. The two sides cannot write a costless contract not to fight. Or, another way to put it is that fighting efforts (e.g., military expenditures in the case of warfare, or litigation expenditures in the case of litigation) are non-contractible. However, contracts to divide the surplus under the threat of conflict, in which the two sides have prepared for fighting, are possible.

For positive efforts $R_{1}$ and $R_{2}$, the probability of player 1 winning the whole surplus $S$ in conflict is

$$
P\left(R_{1}, R_{2}\right)=\frac{\varepsilon R_{1}}{\varepsilon R_{1}+R_{2}}
$$

whereas player $2^{\prime} s$ winning probability is $1-P\left(R_{1}, R_{2}\right)=\frac{R_{2}}{\varepsilon R_{1}+R_{2}}$ and where $\varepsilon>0$ is a source of asymmetry in conflict; when $\varepsilon>1$ player 1 has the advantage and when $\varepsilon<1$ player 2 has the advantage. The sources of asymmetries can vary depending on the context, of course. For the four cases of contests we have discussed, there are many examples of sources of asymmetry. In warfare, a defensive position or technological superiority are typical sources of advantage (Grossman, 2001). In litigation, having the truth with you (Hirshleifer and Osborne, 2001) or the degree of protection of property rights 
are sources of advantage, with a higher $\varepsilon$ implying a higher level of property rights protection (Robson and Skaperdas, 2008). In union-firm interactions, police intervention whether lawful or unlawful, judiciary bias either from an individual judge or the legal system as a whole, public opinion concerning unions, and, for modern times in the U.S., the composition of the NLRB are sources of advantage and disadvantage for the two sides (Gourevitch, 2015; Cooke et al., 1995) In the case of lobbying, access to and disposition from government officials on the part of different lobbies are sources of advantage and disadvantage.

Following Arbatskaya and Mialon (2010), the fighting efforts are functions of two variables. To allow for analytical solutions, we consider the functional form $R_{i}=K_{i}^{\alpha} L_{i}(\alpha \in(0,1) ; i=1,2)$, where $K_{i}$ represents the up-front investment of player $i$ and $L_{i}$ represents their variable effort in the event of conflict. The players first make the up-front investments $K_{1}$ and $K_{2}$ and only if they were to engage in conflict would they choose variable levels of effort $L_{1}$ and $L_{2}$.

For simplicity, we compare two games, one in which Conflict ensues and one in which there is a Bargaining agreement (under the threat of Conflict). 5 The timing of the game under Conflict is the following:

1. Each player chooses whether to enter the game and make up-front investments or not. If a player does not enter the game, he or she receives a payoff of 0 . If only one player chooses to enter, then that player receives the surplus. If both players choose to enter the game, they go to the next stage 2 .

2. The two players simultaneously choose up-front investments $K_{1}$ and $K_{2}$.

3. The players enter into Conflict and choose variable fighting efforts $L_{1}$ and $L_{2}$. The total effort of each player $i$ is determined by $R_{i}=K_{i}^{\alpha} L_{i}$ and (1) provides the probability of winning for player 1.

The players are risk neutral and have constant marginal costs of up-front investments $r_{1}$ and $r_{2}$ and constant marginal costs of variable fighting efforts $w_{1}$ and $w_{2}$. Then, given (1) and the way efforts are determined, the expected

\footnotetext{
${ }^{5}$ We could modify the timing and make the choice between Conflict and Bargaining endogenous to a larger game, with essentially the same results but with some added complication. The equilibrium choices of the two main variables will be the same but there might be some parameters values under which the Bargaining game would not be a subgame perfect equilibrium of the larger game.
} 
payoffs under Conflict are as follows:

$$
\begin{aligned}
& V_{1}^{C}\left(K_{1}, L_{1}, K_{2}, L_{2}\right)=\frac{\varepsilon K_{1}^{\alpha} L_{1}}{\varepsilon K_{1}^{\alpha} L_{1}+K_{2}^{\alpha} L_{2}} S-r_{1} K_{1}-w_{1} L_{1} \\
& V_{2}^{C}\left(K_{1}, L_{1}, K_{2}, L_{2}\right)=\frac{K_{2}^{\alpha} L_{2}}{\varepsilon K_{1}^{\alpha} L_{1}+K_{2}^{\alpha} L_{2}} S-r_{2} K_{2}-w_{2} L_{2}
\end{aligned}
$$

These expressions apply in the event of Conflict, but they also form the threat point of a possible bargaining agreement under the Bargaining game which has the following timing:

1. Each player chooses whether to enter the game and make up-front investments or not. If a player does not enter the game, he or she receives a payoff of 0 . If only one player chooses to enter, then that player receives the surplus. If both players choose to enter the game, they go to the next stage 2 .

2. The two players simultaneously choose up-front investments $K_{1}$ and $K_{2}$.

3. The players arrive at a division of the surplus $S$ to be described below.

When the two sides reach a bargaining agreement, they do not pay the variable costs of conflict, $L_{1}$ and $L_{2}$, although they will already have paid their up-front investments, $K_{1}$ and $K_{2}$. In Bargaining, the disagreement payoffs would be the Conflict payoffs that would be the induced subgame payoffs in (2) for the given combination of $K_{1}$ and $K_{2}$ that the two players have already chosen. Given the disagreement payoffs, here we suppose that the shares of $S$ are determined by the split-the-difference rule. Because of risk neutrality, this rule coincides with the Nash bargaining solution or of any other symmetric bargaining solution, as well as any noncooperative bargaining games (such as alternating-offers games) that might approximate such a rule ${ }^{6}$. (In section five, we examine the case in which one side has all the bargaining power in an ultimatum game).

Define $\beta\left(K_{1}, K_{2}\right)$ as player 1's share under bargaining and $\left(1-\beta\left(K_{1}, K_{2}\right)\right)$ as player 2's share. Given the split-the-difference rule, the share $\beta\left(K_{1}, K_{2}\right)$

\footnotetext{
${ }^{6}$ Anbarci et al. (2002) show how different bargaining solutions can induce different outcomes when the utility possibilities frontier is strictly concave (which is not in our case). Allison (2018) shows how alternating-offers games do not necessarily approximate a bargaining solution and might actually be more efficient that those employing axiomatic solutions as we do here.
} 
is defined by

$$
\begin{gathered}
\beta\left(K_{1}, K_{2}\right) S-P\left(K_{1}^{\alpha} L_{1}^{*}\left(K_{1}, K_{2}\right), K_{2}^{\alpha} L_{2}^{*}\left(K_{1}, K_{2}\right)\right) S+w_{1} L_{1}^{*}\left(K_{1}, K_{2}\right) \\
=\left[1-\beta\left(K_{1}, K_{2}\right)\right] S-\left[1-P\left(K_{1}^{\alpha} L_{1}^{*}\left(K_{1}, K_{2}\right), K_{2}^{\alpha} L_{2}^{*}\left(K_{1}, K_{2}\right)\right)\right] S \\
+w_{2} L_{2}^{*}\left(K_{1}, K_{2}\right)
\end{gathered}
$$

where $L_{i}^{*}\left(K_{1}, K_{2}\right)$ for $i=1,2$ represent the Conflict subgame perfect equilibrium choices of variable efforts for any combination $\left(K_{1}, K_{2}\right)$. The probability of winning for player 1 for any combination $\left(K_{1}, K_{2}\right)$ is thus $P\left(K_{1}^{\alpha} L_{1}^{*}\left(K_{1}, K_{2}\right)\right.$, $\left.K_{2}^{\alpha} L_{2}^{*}\left(K_{1}, K_{2}\right)\right)$. Figure 1 provides a graphical representation of the setting.

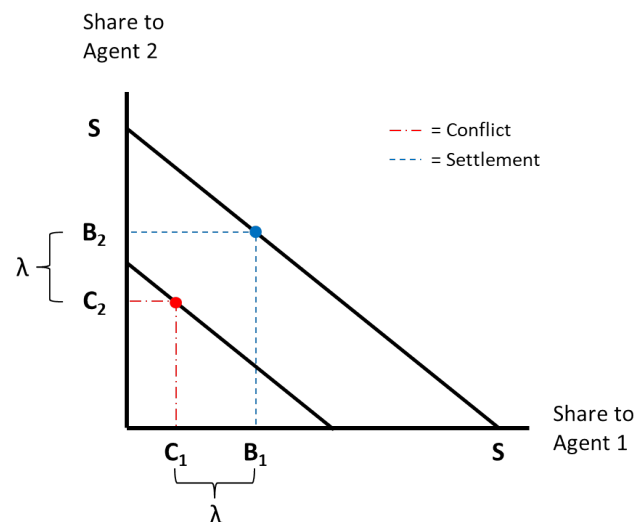

(a) Stronger player 2

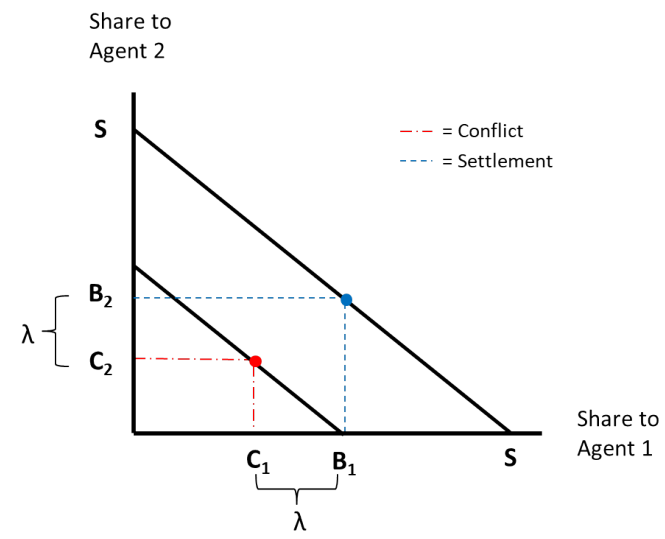

(b) Stronger player 1

Figure 1: The Threat Point and Split-the-Difference Rule

The outside line represents all the possible splits that the two players could achieve under Bargaining. It is Pareto superior to the inside line which is all the possible splits under Conflict. Each player will try to move the inside dot closer to their axis in order to secure a favorable result. Doing so will also drag the outside dot in their direction. Strategically, they accomplish this by committing to preparations (the up-front investments) that will boost their strength under Conflict and thus shift both the conflict split and the bargaining split to their side.

This structure emphasizes the role of threats in the bargaining process. Yet this raises questions for strategy: how do the two sides prepare differently if their aim is to affect the threat point rather than the Conflict outcome? It is far from guaranteed that investments will be the same when settlement is the expected outcome. We will return to this problem momentarily. Given this bargaining rule, it can be shown that the share of player 1 under Bargaining 
is

$\beta\left(K_{1}, K_{2}\right)=P\left(K_{1}^{\alpha} L_{1}^{*}\left(K_{1}, K_{2}\right), K_{2}^{\alpha} L_{2}^{*}\left(K_{1}, K_{2}\right)\right)+\frac{w_{2} L_{2}^{*}\left(K_{1}, K_{2}\right)}{2 S}-\frac{w_{1} L_{1}^{*}\left(K_{1}, K_{2}\right)}{2 S}$

This share equals the player's own probability of winning in case the players were to engage in conflict suitably adjusted by the variable costs of conflict of the two players $\left(w_{i} L_{i}^{*}\left(K_{1}, K_{2}\right)\right.$ for player $\left.i=1,2\right)$. In particular, a higher variable cost of conflict disadvantages a player and advantages his opponent. Both the probabilities of winning and the variable costs of conflict depend on the up-front investments $\left(K_{1}, K_{2}\right)$ in ways that we cannot a priori specify but which we plan to explore. What is clear, however, is that the probabilities of winning under Conflict can be expected to have different properties (in terms of the of their sensitivity to $\left(K_{1}, K_{2}\right)$ ) from those of the sharing function under Bargaining.

The payoff functions for the game under Bargaining are as follows:

$$
\begin{aligned}
V_{1}^{B}\left(K_{1}, K_{2}\right) & =\beta\left(K_{1}, K_{2}\right) S-r_{1} K_{1} \\
V_{2}^{B}\left(K_{1}, K_{2}\right) & =\left[1-\beta\left(K_{1}, K_{2}\right)\right] S-r_{2} K_{2}
\end{aligned}
$$

We now turn to analyzing each of the two games and then to comparing them.

\section{Solving the Conflict Game}

We use backwards induction to solve for a subgame perfect equilibrium.

Begin by assuming a $\left(K_{1}, K_{2}\right)$ pair and let the players maximize their expected payoffs in $(2)$ by the choice of their respective variable efforts $\left(L_{1}, L_{2}\right):^{7}$

${ }^{7}$ Please note that, at this stage, the problem of choosing variable efforts is equivalent to choosing total efforts $\left(R_{1}, R_{2}\right)$ (that, by (1), equal $\left(K_{1}^{\alpha} L_{1}, K_{2}^{\alpha} L_{2}\right)$ ) but with $K_{1}$ and $K_{2}$ fixed. The constrained payoffs are then

$$
\begin{aligned}
& V_{1}^{C}\left(R_{1}, R_{2} \quad \mid \quad\left(K_{1}, K_{2}\right)\right)=\frac{\varepsilon R_{1}}{\varepsilon R_{1}+R_{2}} S-r_{1} K_{1}-\frac{w_{1}}{K_{1}^{\alpha}} R_{1} \\
& V_{2}^{C}\left(R_{1}, R_{2} \quad \mid \quad\left(K_{1}, K_{2}\right)\right)=\frac{R_{2}}{\varepsilon R_{1}+R_{2}} S-r_{2} K_{2}-\frac{w_{2}}{K_{2}^{\alpha}} R_{2}
\end{aligned}
$$

What is notable from this re-writing of the problem at this stage of the game is that the up-front investments are interpretable as reducing the marginal cost of total effort ( $\frac{w i}{K_{i}^{\alpha}}$ for player $i$ ). That is, in the conflict and contest literature, marginal costs could be thought of as being partly the result of previous investments and endowments that the players have inherited from the past. 


$$
\begin{aligned}
& V_{1}^{C}\left(L_{1}, L_{2} \quad \mid \quad K_{1}, K_{2}\right)=\frac{\varepsilon K_{1}^{\alpha} L_{1}}{\varepsilon K_{1}^{\alpha} L_{1}+K_{2}^{\alpha} L_{2}} S-r_{1} K_{1}-w_{1} L_{1} \\
& V_{2}^{C}\left(L_{1}, L_{2} \quad \mid \quad K_{1}, K_{2}\right)=\frac{K_{2}^{\alpha} L_{2}}{\varepsilon K_{1}^{\alpha} L_{1}+K_{2}^{\alpha} L_{2}} S-r_{2} K_{2}-w_{2} L_{2}
\end{aligned}
$$

The first-order conditions imply

$K_{1}^{\alpha} K_{2}^{\alpha} L_{2}^{*}=\frac{w_{1}\left(\varepsilon K_{1}^{\alpha} L_{1}^{*}+K_{2}^{\alpha} L_{2}^{*}\right)^{2}}{S \varepsilon} \quad$ and $\quad K_{1}^{\alpha} K_{2}^{\alpha} L_{1}^{*}=\frac{w_{2}\left(\varepsilon K_{1}^{\alpha} L_{1}^{*}+K_{2}^{\alpha} L_{2}^{*}\right)^{2}}{S \varepsilon}$

Solving simultaneously, we have $L_{1}^{*}=\omega L_{2}^{*}$ (where $\omega \equiv \frac{w_{2}}{w_{1}}$ ) which makes for the following subgame perfect equilibrium choices:

$$
\begin{aligned}
& L_{1}^{*}\left(K_{1}, K_{2}\right)=\frac{\varepsilon \omega K_{1}^{\alpha} K_{2}^{\alpha}}{w_{1}\left(\varepsilon \omega K_{1}^{\alpha}+K_{2}^{\alpha}\right)^{2}} S \\
& L_{2}^{*}\left(K_{1}, K_{2}\right)=\frac{\varepsilon K_{1}^{\alpha} K_{2}^{\alpha}}{w_{1}\left(\varepsilon \omega K_{1}^{\alpha}+K_{2}^{\alpha}\right)^{2}} S
\end{aligned}
$$

Just as with $\varepsilon$, the higher is the ratio of $\operatorname{costs} \omega$ the better it is for player 1 . This makes the winning probability of player 1 a simple function of $K_{1}$ and $K_{2}$ :

$$
P^{*}\left(K_{1}, K_{2}\right)=\frac{\varepsilon \omega K_{1}^{\alpha}}{\varepsilon \omega K_{1}^{\alpha}+K_{2}^{\alpha}}
$$

Continuing backwards, the players choose optimal up-front investments, $K_{1}$ and $K_{2}$ for the case of open conflict. First order conditions for this equilibrium imply:

$\varepsilon \omega K_{1}^{* 2 \alpha-1} K_{2}^{* \alpha}=\frac{r_{1}\left(\varepsilon \omega K_{1}^{* \alpha}+K_{2}^{* \alpha}\right)^{3}}{2 \alpha \varepsilon \omega S} \quad$ and $\quad K_{1}^{* \alpha} K_{2}^{* 2 \alpha-1}=\frac{r_{2}\left(\varepsilon \omega K_{1}^{* \alpha}+K_{2}^{* \alpha}\right)^{3}}{2 \alpha \varepsilon \omega S}$

resulting in the relationship $K_{1}^{*}=(\varepsilon \omega \rho)^{\frac{1}{1-\alpha}} K_{2}^{*}=\theta \rho K_{2}^{*}$ where $\rho \equiv r_{2} / r_{1}$ and $\theta \equiv(\varepsilon \omega)^{\frac{1}{1-\alpha}} \rho^{\frac{\alpha}{1-\alpha}}$. The parameter $\theta$ represents a summary indicator of the asymmetry across the two players which, as we shall see, enters in all the key equilibrium variables of the model. In terms of the components of $\theta$ the asymmetry in the contest success function $(\varepsilon)$ plays a similar role to the ratio of marginal costs in variable efforts $(\omega)$, whereas the ratio in marginal costs in up-front investments $(\rho)$ has a smaller exponent (given that $\alpha<1$ ). Overall, as with its component variables, $\theta>1$ implies player 1 has the advantage whereas $\theta<1$ implies that player 2 has the advantage.

We can show that equilibrium up-front investments equal: 


$$
\begin{aligned}
& K_{1}^{*}=\frac{2 \alpha \theta^{2}}{r_{1}(\theta+1)^{3}} S \\
& K_{2}^{*}=\frac{2 \alpha \theta}{r_{2}(\theta+1)^{3}} S
\end{aligned}
$$

Then, the (ex-ante) equilibrium probability of player 1 winning reduces to a function of the three sources of asymmetry:

$$
P\left(K_{1}^{*}, K_{2}^{*}\right)=\frac{\theta}{\theta+1}
$$

By substitution, we can obtain the subgame equilibrium variable fighting efforts:

$$
\begin{aligned}
& L_{1}^{*} \equiv L_{1}^{*}\left(K_{1}^{*}, K_{2}^{*}\right)=\frac{\theta}{w_{1}(\theta+1)^{2}} S \\
& L_{2}^{*} \equiv L_{2}^{*}\left(K_{1}^{*}, K_{2}^{*}\right)=\frac{\theta}{w_{2}(\theta+1)^{2}} S
\end{aligned}
$$

As already noted, variable fighting efforts differ across the two players only in terms of the ratio of marginal costs of these efforts (i.e., $L_{1}^{*}=\omega L_{2}^{*}$ ). By contrast, the difference in up-front investments does not just depend on the ratio of marginal costs of these efforts $(\rho)$ but depends on the overall asymmetry parameter $\theta$ as well so that, as previously noted, $K_{1}^{*}=\theta \rho K_{2}^{*}$. As we shall see later, this asymmetry in up-front investments does not exist in the case of Bargaining.

Using the equilibrium values for the efforts, the expected Conflict equilibrium payoffs can be shown to be:

$$
\begin{aligned}
& V_{1}^{C *}=\frac{\theta^{2}(\theta+1-2 \alpha)}{(\theta+1)^{3}} S \\
& V_{2}^{C *}=\frac{\theta(1-2 \alpha)+1}{(\theta+1)^{3}} S
\end{aligned}
$$

Note for $2 \alpha \leq 1$, both payoffs are guaranteed to be positive. However, for $2 \alpha>1$ they are not guaranteed to be so and therefore there might be an incentive for one player to not enter the Conflict game at all. In particular, when player 1 has the advantage $(\theta>1)$, it can be seen from (11) that player 1 's equilibrium payoff is always positive but for player 2 it is only so if $\theta<$ $\frac{1}{2 \alpha-1}$. Similarly, when player 2 has the advantage $V_{2}^{*}$ is always positive but $V_{1}^{*}$ is positive only if $\theta>2 \alpha-1$. Thus, for $\alpha>\frac{1}{2}$ a Conflict equilibrium 
exists only if one player does not have too high an advantage over the other; otherwise the weaker player will choose not to enter the game.

We summarize the main properties of the Conflict game equilibrium as a Proposition.

Proposition 1: (i) A unique equilibrium of the Conflict game exists in which both players participate when $\alpha \leq 1 / 2$ and when $\theta \in\left(2 \alpha-1, \frac{1}{2 \alpha-1}\right)$ with $\alpha>1 / 2$. When $\alpha>1 / 2$ and $\theta \in(0,2 \alpha-1)$, player 1 has negative payoff in the Conflict game. When $\alpha>1 / 2$ and $\theta \in\left(\frac{1}{2 \alpha-1}, \infty\right)$, player 2 has negative payoff in the Conflict game. The equilibrium payoffs are described in (11).

(ii) The equilibrium winning probabilities favor the stronger player so that $P\left(K_{1}^{*}, K_{2}^{*}\right)=\frac{\theta}{\theta+1}$ (which is greater than $1 / 2$ when $\theta>1$ and less than $1 / 2$ when $\theta<1$ )

(iii) The effects of the asymmetry parameter $\theta$ on the equilibrium up-front investments are as follows: $\frac{\partial K_{1}^{*}}{\partial \theta} \gtreqless 0$ as $\theta \lesseqgtr 2$ and $\frac{\partial K_{2}^{*}}{\partial \theta} \gtreqless 0$ as $\theta \lesseqgtr \frac{1}{2}$

(iv) The effects of the asymmetry parameter $\theta$ on the equilibrium variable conflict efforts are as follows: Both $\frac{\partial L_{1}^{*}}{\partial \theta} \gtreqless 0$ and $\frac{\partial L_{2}^{*}}{\partial \theta} \gtreqless 0$ as $\theta \lesseqgtr 1$. (Proof is in the Appendix)

Consistent with the greater asymmetry for the up-front investments, their levels are maximized at an asymmetry parameter $\theta$ that favors the player with the advantage (2 for player 1 and $1 / 2$ for player 2 , part (iii) of Proposition), whereas the variable fighting efforts are maximized at the symmetric level $\theta=1$.

\section{Solving the Bargaining Game}

In the Bargaining game, the payoff functions are as in (5) with the bargaining share of player $1, \beta\left(K_{1}, K_{2}\right)$ as defined in (4) and the continuation variable fighting efforts $L_{i}^{*}\left(K_{1}, K_{2}\right) s$ as in (6). It can then be shown that $\beta\left(K_{1}, K_{2}\right)=$ $\frac{\varepsilon \omega K_{1}^{\alpha}}{\varepsilon \omega K_{1}^{\alpha}+K_{2}^{\alpha}}$ which is the same winning probability of player 1 in the Conflict game conditional on the up-front investments (i.e., $P^{*}\left(K_{1}, K_{2}\right)$ in $\left.(7)\right)$. The payoff functions under Bargaining then reduce to:

$$
\begin{aligned}
& V_{1}^{B}\left(K_{1}, K_{2}\right)=\frac{\varepsilon \omega K_{1}^{\alpha}}{\varepsilon \omega K_{1}^{\alpha}+K_{2}^{\alpha}} S-r_{1} K_{1} \\
& V_{2}^{B}\left(K_{1}, K_{2}\right)=\frac{K_{2}^{\alpha}}{\varepsilon \omega K_{1}^{\alpha}+K_{2}^{\alpha}} S-r_{2} K_{2}
\end{aligned}
$$


The Nash equilibrium conditions imply:

$$
\begin{aligned}
K_{1}^{\alpha-1} K_{2}^{\alpha} & =\frac{r_{1}\left(\varepsilon \omega K_{1}^{\alpha}+K_{2}^{\alpha}\right)^{2}}{\alpha \varepsilon \omega S} \quad \text { and } \\
K_{1}^{\alpha} K_{2}^{\alpha-1} & =\frac{r_{2}\left(\varepsilon \omega K_{1}^{\alpha}+K_{2}^{\alpha}\right)^{2}}{\alpha \varepsilon \omega S}
\end{aligned}
$$

which produce the relationship $\bar{K}_{1}=\rho \bar{K}_{2}$ and the following equilibrium expressions:

$$
\begin{aligned}
& \bar{K}_{1}=\frac{\alpha \theta^{1-\alpha}}{r_{1}\left(\theta^{1-\alpha}+1\right)^{2}} S \\
& \bar{K}_{2}=\frac{\alpha \theta^{1-\alpha}}{r_{2}\left(\theta^{1-\alpha}+1\right)^{2}} S
\end{aligned}
$$

The equilibrium share of player 1 then equals:

$$
\beta\left(\bar{K}_{1}, \bar{K}_{2}\right)=\frac{\theta^{1-\alpha}}{\theta^{1-\alpha}+1}
$$

Note that this is less than $P\left(K_{1}^{*}, K_{2}^{*}\right)=\frac{\theta}{\theta+1}$ when $\theta>1$ and greater than $P\left(K_{1}^{*}, K_{2}^{*}\right)$ when $\theta<1$. That is, the player with the advantage always receives a lower share of the surplus in the Bargaining game than she or he has equilibrium probability of winning in the Conflict game.

The equilibrium payoffs under Bargaining are then as follows:

$$
\begin{aligned}
\bar{V}_{1}^{B} & =\frac{\theta^{1-\alpha}\left(\theta^{1-\alpha}+1-\alpha\right)}{\left(\theta^{1-\alpha}+1\right)^{2}} S \\
\bar{V}_{2}^{B} & =\frac{\theta^{1-\alpha}(1-\alpha)+1}{\left(\theta^{1-\alpha}+1\right)^{2}} S
\end{aligned}
$$

Contrary to the case of the Conflict payoffs, the Bargaining payoffs are always positive and therefore both players would have an incentive to participate in the Bargaining game.

We summarize the main results of the Bargaining game in the following Proposition.

Proposition 2: $\quad$ (i) A unique equilibrium of the Bargaining game exists in which both players participate for all parameter values. The equilibrium payoffs are described in (15).

(ii) The equilibrium shares under bargaining favor the stronger player so that $\beta\left(\bar{K}_{1}, \bar{K}_{2}\right)=\frac{\theta^{1-\alpha}}{\theta^{1-\alpha}+1}$ (which is greater than $1 / 2$ when $\theta>1$ and less than $1 / 2$ when $\theta<1)$. 
(iii) The effects of the asymmetry parameter $\theta$ on the equilibrium up-front investments are identical for the two players so that: $\frac{\partial \bar{K}_{1}}{\partial \theta} \gtreqless 0$ and $\frac{\partial \bar{K}_{2}}{\partial \theta} \gtreqless 0$ as $\theta \lesseqgtr 1$.

(Proof is in the Appendix)

Contrary to the equilibrium up-front investments under Conflict, equilibrium up-front investments under Bargaining, as shown under (iii) move together as a function of the asymmetry parameter $\theta$. They are both maximal when strength is equal $(\theta=1)$. This results is similar to what occurs in simple contests where the efforts are greatest under symmetry but become lower as the asymmetry increases (see, for example, Konrad, 2009). As we shall shortly see, this is a key attribute in comparing payoffs under Conflict and Bargaining, to which we now turn.

\section{Comparing Conflict to Bargaining}

In Comparing Conflict to Bargaining, there are at least two issues of interest. One is distributional. Are the probabilities of winning under Conflict and the shares received under Bargaining similar? How do the up-front investments differ in the two games and how do the variable fighting efforts under Conflict influence outcomes? The second issue that is ultimately most important, and partly depends on the first one, is whether one side would ever prefer Conflict to Bargaining. Given that Conflict involves the extra variable effort costs, for Conflict to be ex ante preferable by at least one player a combination of low enough up-front investments under Conflict and a high enough probability of winning (relative to the share under Bargaining) would be necessary.

We summarize the main comparisons between Conflict and Bargaining in Proposition 3.

Proposition 3: (i) Up-front investments under Conflict differ more $\left(K_{1}^{*}=\theta \rho K_{2}^{*}\right)$ than up-front investments under Bargaining $\left(\bar{K}_{1}=\rho \bar{K}_{2}\right)$.

(ii) The stronger player has a higher probability of winning under Conflict than he or she has as a share of the surplus under Bargaining (i.e., $P\left(K_{1}^{*}, K_{2}^{*}\right)=\frac{\theta}{\theta+1} \gtreqless \frac{\theta^{1-\alpha}}{\theta^{1-\alpha}+1}=\beta\left(\bar{K}_{1}, \bar{K}_{2}\right)$ as $\left.\theta \gtreqless 1\right)$.

(iii) The strongest player prefers Conflict to Bargaining for high enough $\alpha$ and high enough asymmetry (sufficiently low or sufficiently high $\theta$ ) in their favor.

(iv) Also for high enough $\alpha$ and sufficiently low or sufficiently high $\theta$ total equilibrium payoffs under Bargaining can be lower than under Conflict.

(Proof is in the Appendix) 
By part (i) of the Proposition, up-front investments under Conflict, are more different the greater is the asymmetry of the two players (i.e., the further $\theta$ is away from 1 ), whereas under Bargaining up-front investments differ only to the extent that the marginal costs of effort differ $\left(\bar{K}_{1}=\rho \bar{K}_{2}\right)$. Figure 2 shows how for $\rho=1$ and $\alpha=0.75$, the up-front investments under the two games compare.

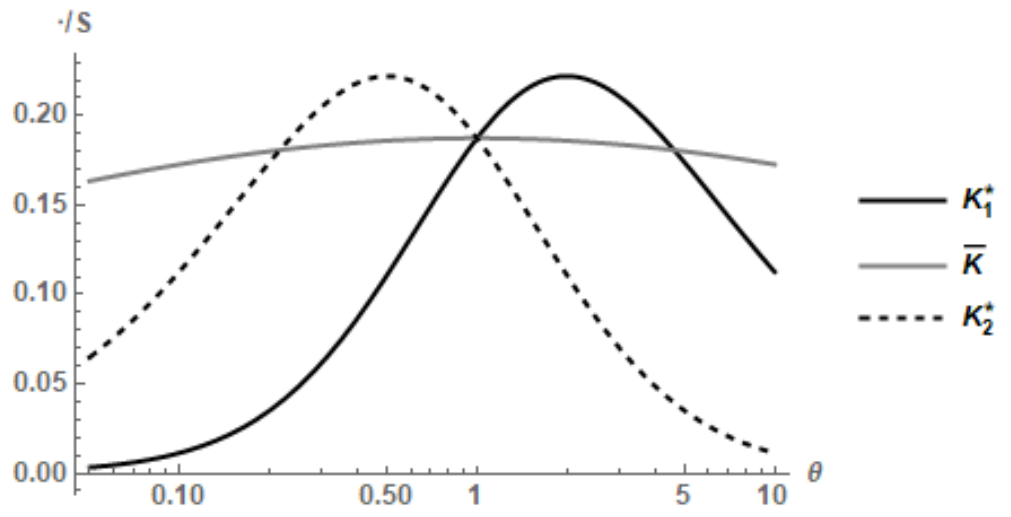

Figure 2: K comparison, $\alpha=0.75, \rho=1$

Given that $\rho=1, \bar{K}_{1}=\bar{K}_{2}$ for all values of $\theta$; but the difference between the two up-front investment under Conflict $\left(K_{1}^{*}\right.$ and $\left.K_{2}^{*}\right)$ becomes larger the further $\theta$ is away from 1 (and the greater is the asymmetry between the players). Moreover, the total level of up-front investments under Conflict becomes smaller and lower than the up-front investments under Bargaining.

The greater asymmetry under Conflict for up-front investments along with the relative symmetry of variable fighting efforts $\left(L_{1}^{*}=\omega L_{2}^{*}\right)$ implies (part (ii) of Proposition) that the stronger player has a higher probability of winning under Conflict than he or she has as a share of the surplus under Bargaining.

Therefore, the lower cost of up-front investments for a sufficiently strong player under Conflict (compared to Bargaining) but a higher probability of winning under Conflict (compared to the share under Bargaining) induces a payoff under Conflict that is higher than that under Bargaining (part (iii)).

Figure 3 partitions $(\theta, \alpha)$ into regions that we expect to be induced given what we know about the payoffs under the different games. In the darker regions, the weaker player has a negative payoff under Conflict (Proposition 1, part (i)) and can be expected not to participate given that the stronger player prefers Conflict to Bargaining. Since the stronger player is the sole participant in this case, he or she receives the whole surplus. In the less 


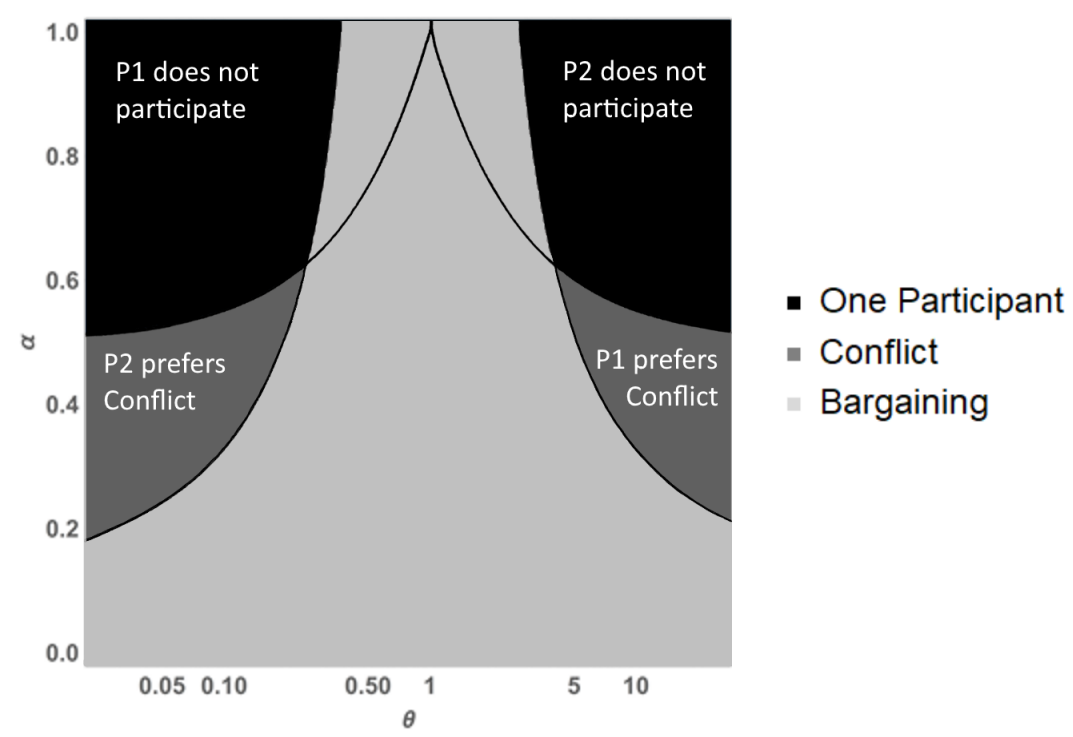

Figure 3: Outcome Regions

dark regions in which the stronger player prefers Conflict, the weaker player participates. Finally, in the remaining areas without strong asymmetries or with low returns on up-front investments (low $\alpha$ ), Bargaining is preferred by both sides.

Thus Conflict is possible when asymmetry is high enough and one side may even prefer it. Interestingly, this also implies that it is possible to have stout participants and peaceful settlement. The key is to create balance between agents and eliminate sources of bias in the overall environment.

In figure 4 we include regions that actually involve higher total payoffs under Conflict than under Bargaining. As can be expected these regions are strictly within the region that the stronger player prefers Conflict

\section{$5 \quad$ Ultimatum Bargaining}

We now alter the game slightly to allow for positional dominance in the bargaining structure itself; that is, we consider the case of ultimatum bargaining. We will see that the essential results of this model are robust to such a change, and that relaxing the symmetry of the process that is characteristic of Nash bargaining places greater power in the hand of the proposer. Furthermore, conflict becomes less likely when the proposer is strong, but more likely when the proposer is weak. This is because there is an additional first mover advantage in bargaining that makes a strong player very likely to prefer settlement if they gain the benefit of this additional share, and highly 


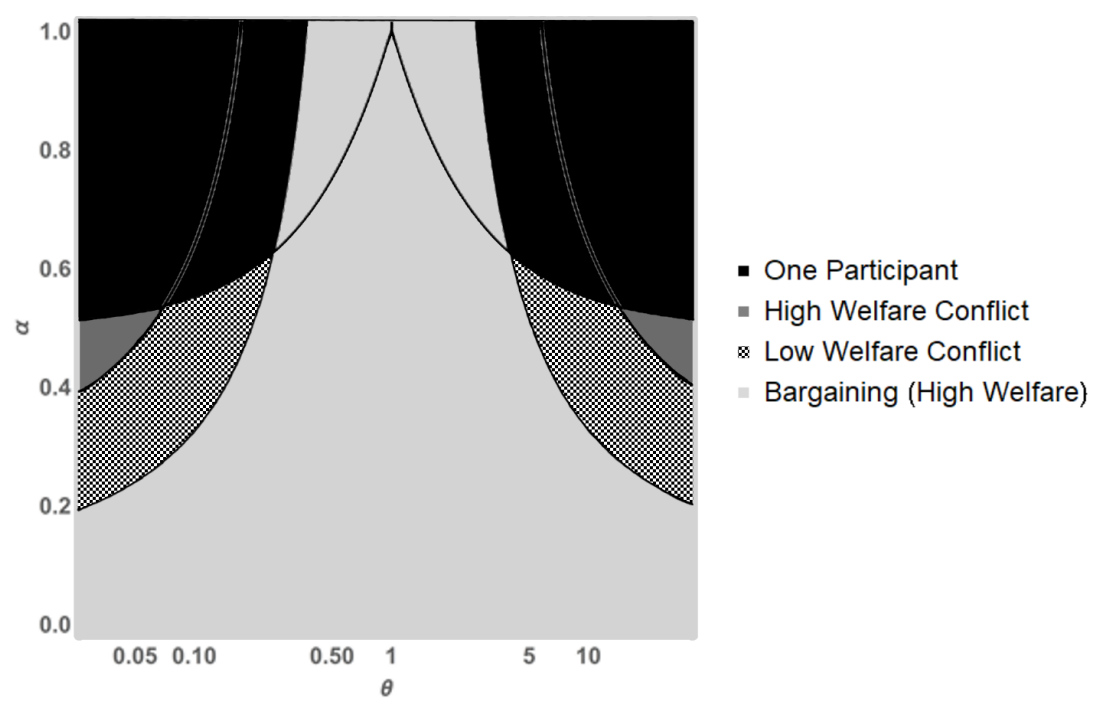

Figure 4: Welfare Regions

likely to prefer conflict if they must give it up.

Suppose player 1 is the proposer. To accomplish equilibrium settlement, she must propose share $x$ to herself and $1-x$ to player 2 such that player 2 is indifferent between settlement and conflict. Naturally, this allows the proposer to extract all the gains from avoiding conflict. The worked out solution and equilibrium expressions are in the Appendix, here we highlight the results and intuition of the extension.

The ultimatum bargaining structure induces players to be more defensive with their up-front investments. Figure 5 shows that when player 1 is the proposer, investment is higher than the baseline solution for low theta values, and lower for high theta values. The pattern is flipped for when player two is the proposer. This means that proposers use their first mover advantage to shore up their bargaining position when they are otherwise disadvantaged. They do not use it to be more aggressive when they already have an advantage.

The first mover advantage under ultimatum bargaining is shown in Figure 6 along with the difference between beta from the baseline model and $x$, the equilibrium share of the prize going to player 1 under this alternative structure. One can see that being the first mover confers a rather large advantage in this version of the game. The effect of the additional asymmetry introduced in this extension compared to the base model is smaller but still substantial.

Moving on to the question of which outcome to expect, our essential result 


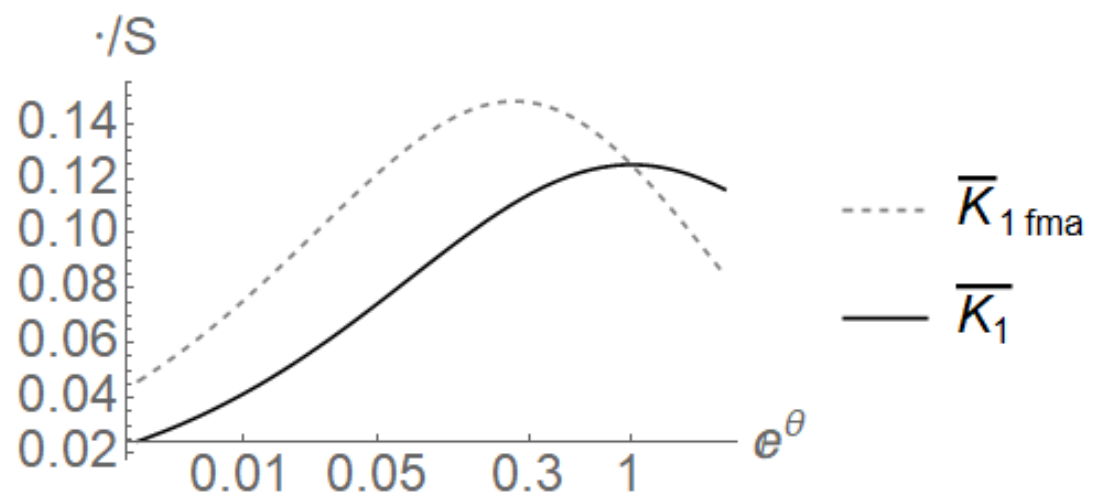

Figure 5: $\bar{K}_{1}$ Nash vs. Ultimatum Bargaining

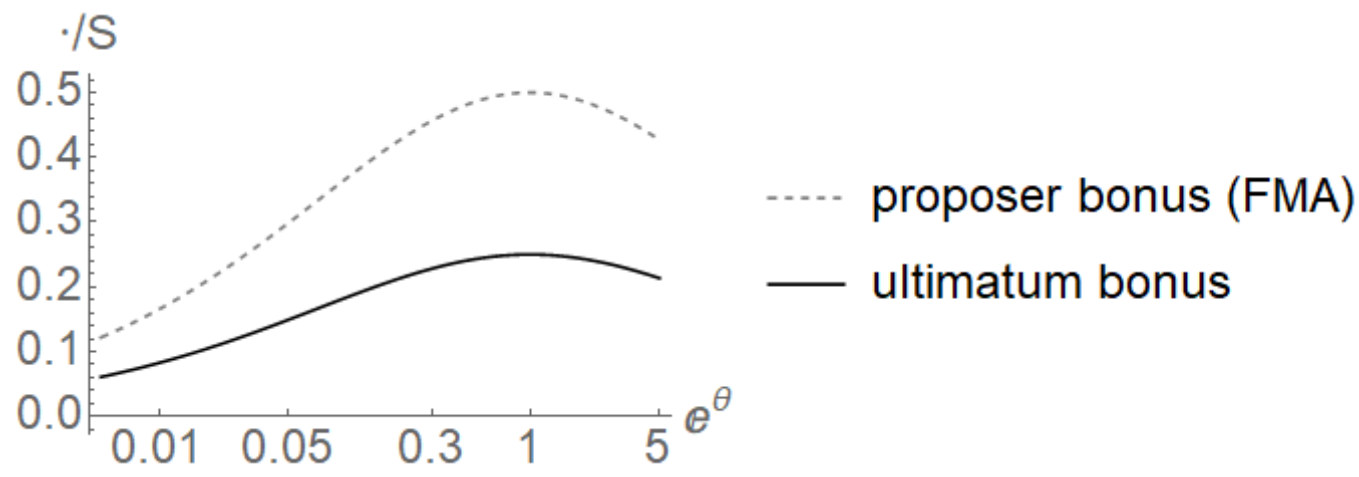

Figure 6

that one player may prefer conflict to settlement still holds with ultimatum bargaining. The parameter values necessary to see this outcome become more extreme, however, when the proposer already enjoys an advantage in terms of $\theta$. This is because their first mover advantage is only realized in settlement and the gains from conflict drop to nothing for all but extremely high values of $\theta$ where winning is almost a sure thing with little effort.

The flip side of this coin is interesting. Suppose that the proposer is instead disadvantaged in $\theta$. This player most surely wants settlement, yet their opponent, the responder, will prefer to commit to Conflict. Such a responder has to invest so much to overcome the first mover advantage and get a decent bargaining outcome that they are better off committing to much lower optimal conflict investments and bearing the additional costs of contest efforts. Figure 7 shows that conflict is now the predominant outcome whenever the proposer is weak. The gray region to the right of $\theta=1$ represents conflict desired by player 1 if they are the responder, the gray region to the left 


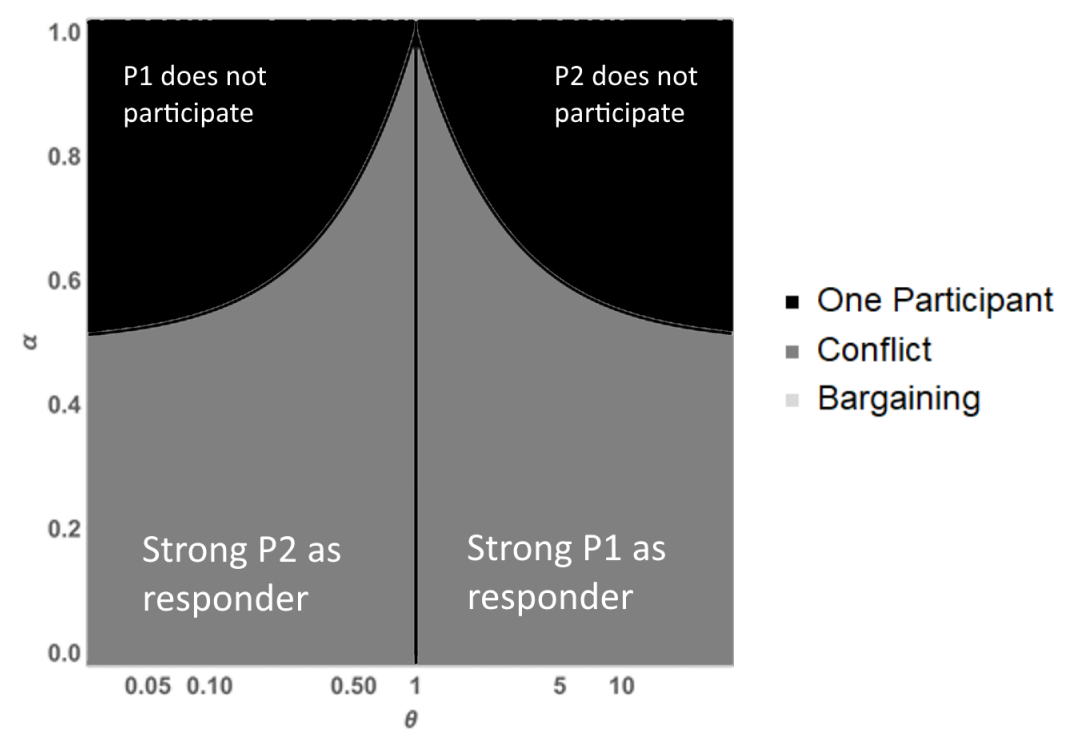

Figure 7: Outcome Regions, Ultimatum Bargaining

represents conflict desired by player 2 if they are the responder. As before, the black regions represent parameter values for which one player wants conflict, but the other chooses not to participate because conflict would yield a negative payoff.

\section{Concluding Remarks}

We have seen how asymmetries in power can induce conflict. In some settings power asymmetries are not due to technology but are, at least, partly determined by policy. In labor relations, for example, how the courts and other state institutions treat labor unions relative to management is largely a result of government policies. In lobbying and litigation governments can also influence the relative power of contestants. Therefore, to the extent that one wishes to avoid conflict, one possible policy implication is to maintain balanced institutions. This paper highlights that the threat of conflict can be high in highly biased environments and low in more balanced environments. It is possible to have two strong and well prepared agents interacting peacefully when the underlying rules of the game are balanced. Moreover, the strength of both is required to prevent the stronger from taking advantage of the weaker in outright conflict. 


\section{References}

[1] Allison, B. A. Do players prefer to bargain noncooperatively in the shadow of conflict?

[2] Anbarci, N., Skaperdas, S., and Syropoulos, C. Comparing bargaining solutions in the shadow of conflict: How norms against threats can have real effects. Journal of Economic Theory 106, 1 (2002), 1-16.

[3] Arbatskaya, M., and Mialon, H. M. Multi-activity contests. Economic Theory 43 (2010), 2343.

[4] Arbatskaya, M., and Mialon, H. M. Dynamic multi-activity contests. The Scandinavian Journal of Economics 114, 2 (2012), 520538.

[5] Beviá, C., And Corchón, L. C. Peace agreements without commitment. Games and Economic Behavior 68, 2 (2010), 469-487.

[6] Brandeis, L. D., And Lewis, C. M. The Curse of Bigness: Miscellaneous Papers of Louis D. Brandeis. Viking Press, 1934.

[7] Cooke, W. N., Mishra, A. K., Spreitzer, G. M., And TSCHIRHART, M. The determinants of nlrb decision-making revisited. ILR Review 48, 2 (1995), 237-257.

[8] Cramton, P., and Tracy, J. Unions, bargaining and strikes. Edward Elgar, 2002.

[9] Fearon, J. D. Rationalist explanations for war. International organization 49, 3 (1995), 379-414.

[10] Fernandez, R., And Glazer, J. Striking for a bargain between two completely informed agents. The American Economic Review (1991), 240-252.

[11] Garfinkel, M. R., And Skaperdas, S. Conflict without misperceptions or incomplete information: how the future matters. Journal of conflict resolution 44, 6 (2000), 793-807.

[12] Garfinkel, M. R., And Syropoulos, C. Problems of commitment in arming and war: how insecurity and destruction matter. Public Choice (2018), 1-21. 
[13] Gourevitch, A. Police work: The centrality of labor repression in american political history. Perspectives on Politics 13, 3 (2015), 762773.

[14] Grossman, H. I. The creation of effective property rights. American Economic Review 91, 2 (2001), 347-352.

[15] Herbst, L., Konrad, K. A., And Morath, F. Balance of power and the propensity of conflict. Games and Economic Behavior 103 (2017), $168-184$.

[16] Hirshleifer, J., And Osborne, E. Truth, effort, and the legal battle. Public Choice 108, 1-2 (2001), 169-195.

[17] Kimbrough, E. O., Rubin, J., Sheremeta, R. M., And Shields, T. W. Commitment problems in conflict resolution. Journal of Economic Behavior 85 Organization 112 (2015), 33-45.

[18] Kimbrough, E. O., Sheremeta, R. M., and Shields, T. W. When parity promotes peace: Resolving conflict between asymmetric agents. Journal of Economic Behavior \& Organization 99 (2014), 96108.

[19] Konrad, K. A., ET AL. Strategy and dynamics in contests. OUP Catalogue (2009).

[20] McBride, M., And Skaperdas, S. Conflict, settlement, and the shadow of the future. Journal of Economic Behavior \& Organization 105 (2014), 75-89.

[21] McBride, M. T., And Skaperdas, S. Explaining conflict in lowincome countries: Incomplete contracting in the shadow of the future.

[22] NAsh JR, J. F. The bargaining problem. Econometrica: Journal of the Econometric Society (1950), 155-162.

[23] O'Sullivan, C. D. Colin Powell: American power and intervention from Vietnam to Iraq. Rowman \& Littlefield Publishers, 2009.

[24] Rai, B. K., And Sarin, R. Generalized contest success functions. Economic Theory 40, 1 (2009), 139-149.

[25] Robson, A., And Skaperdas, S. Costly enforcement of property rights and the coase theorem. Economic Theory 36, 1 (2008), 109-128. 
[26] SÁnchez-Pagés, S. Conflict as a part of the bargaining process. The Economic Journal 119, 539 (2009), 1189-1207.

[27] Schelling, T. C. The strategy of conflict. Harvard university press, 1980.

[28] Sieberg, K., Clark, D., Holt, C., Nordstrom, T., and Reed, W. An experimental analysis of asymmetric power in conflict bargaining. Games 4, 3 (2013), 375-397.

[29] Skaperdas, S. Bargaining versus fighting. Defence and Peace Economics 17, 6 (2006), 657-676.

[30] Smith, A. C., Houser, D., Leeson, P. T., and Ostad, R. The costs of conflict. Journal of Economic Behavior 85 Organization 97 (2014), 61-71.

[31] Wagner, R. H. Peace, war, and the balance of power. American Political Science Review 88, 3 (1994), 593-607.

[32] Wittman, D. How a war ends: A rational model approach. Journal of Conflict Resolution 23, 4 (1979), 743-763.

[33] Wrangham, R. W., And Glowacki, L. Intergroup aggression in chimpanzees and war in nomadic hunter-gatherers. Human Nature 23, 1 (2012), 5-29. 


\section{Appendix}

\section{Proof of Proposition 1:}

Part (i): The equilibrium and the conditions under which the players have positive or negative equilibrium payoffs have been derived in the main text. Corner solutions are thus handled and there is only one interior optimum for each choice variable. Second derivatives confirm that these optima are maxima:

$$
\begin{gathered}
\frac{\partial^{2}}{\partial L_{1}^{2}}\left[V_{1}^{C}\left(K_{1}, K_{2}, L_{1}, L_{2}\right)\right]=\frac{-2 S \varepsilon^{2} K_{1}^{2 \alpha} K_{2}^{\alpha} L_{2}}{\left(\varepsilon K_{1}^{\alpha} L_{1}+K_{2}^{\alpha} L_{2}\right)^{3}} \\
\frac{\partial^{2}}{\partial K_{1}^{2}}\left[V_{1}^{C}\left(K_{1}, K_{2}, L_{1}^{*}\left(K_{1}, K_{2}\right), L_{2}^{*}\left(K_{1}, K_{2}\right)\right)\right]= \\
\frac{2 \alpha S \varepsilon^{2} \omega^{2} K_{1}^{2 \alpha-2} K_{2}^{\alpha}}{\left(\varepsilon \omega K_{1}^{\alpha}+K_{2}^{\alpha}\right)^{4}}\left((2 \alpha-1) K_{2}^{\alpha}-(\alpha+1) \varepsilon \omega K_{1}^{\alpha}\right)
\end{gathered}
$$

which is negative as long as:

$$
(2 \alpha-1) K_{2}^{\alpha}<(\alpha+1) \varepsilon \omega K_{1}^{\alpha}
$$

looking at the optimum point, the condition becomes:

$$
\begin{aligned}
(2 \alpha-1) K_{2}^{\alpha} & <(\alpha+1) \varepsilon \omega(\varepsilon \omega \rho)^{\frac{\alpha}{1-\alpha}} K_{2}^{\alpha} \\
(2 \alpha-1) & <(\alpha+1)(\varepsilon \omega)^{\frac{1}{1-\alpha}} \rho^{\frac{\alpha}{1-\alpha}} \\
(2 \alpha-1) & <(\alpha+1) \theta
\end{aligned}
$$

which holds when $\alpha \leq 1 / 2$ and when $\alpha>1 / 2$ with $\theta>2 \alpha-1$ as assumed. Similar expressions for player two yield the same outcomes.

Part (ii): as shown in (9)

Part (iii): Suppose $K_{1}^{*}=\frac{2 \alpha \theta^{2}}{r_{1}(\theta+1)^{3}} S$ and $K_{2}^{*}=\frac{2 \alpha \theta}{r_{2}(\theta+1)^{3}} S$ as derived in the text.

$$
\begin{aligned}
\frac{\partial K_{1}^{*}}{\partial \theta}=2 \alpha S / r_{1}\left(\frac{2 \theta}{(\theta+1)^{3}}-\frac{3 \theta^{2}}{(\theta+1)^{4}}\right) & >0 \\
\frac{2 \theta-\theta^{2}}{(\theta+1)^{4}} & >0 \\
2 & >\theta
\end{aligned}
$$




$$
\begin{aligned}
\frac{\partial K_{2}^{*}}{\partial \theta}=2 \alpha S / r_{2}\left(\frac{1}{(\theta+1)^{3}}-\frac{3 \theta}{(\theta+1)^{4}}\right) & >0 \\
\frac{1-2 \theta}{(\theta+1)^{4}} & >0 \\
1 / 2 & >\theta
\end{aligned}
$$

Therefore, $\frac{\partial K_{1}^{*}}{\partial \theta} \gtreqless 0$ as $\theta \lesseqgtr 2$ and $\frac{\partial K_{2}^{*}}{\partial \theta} \gtreqless 0$ as $\theta \lesseqgtr \frac{1}{2}$.

Part (iv): Suppose $L_{i}^{*}=\frac{\theta}{w_{i}(\theta+1)^{2}} S$ for $i \in\{1,2\}$ as derived in the text.

$$
\begin{aligned}
\frac{\partial L_{i}^{*}}{\partial \theta}=S / w_{i}\left(\frac{1}{(\theta+1)^{2}}-\frac{2 \theta}{(\theta+1)^{3}}\right) & >0 \\
\frac{1-\theta}{(\theta+1)^{3}} & >0 \\
1 & >\theta
\end{aligned}
$$

Therefore, both $\frac{\partial L_{1}^{*}}{\partial \theta} \gtreqless 0$ and $\frac{\partial L_{2}^{*}}{\partial \theta} \gtreqless 0$ as $\theta \lesseqgtr 1$.

\section{Proof of Proposition 2:}

Part (i): Equilibrium payoffs in (15) are nonnegative for all parameter values, hence there is only the unique interior solution derived in the main text. Second derivatives confirm that these optima are maxima:

$$
\frac{\partial^{2}}{\partial K_{1}^{2}}\left[V_{1}^{B}\left(K_{1}, K_{2}\right)\right]=\frac{\alpha S \varepsilon \omega K_{2}^{\alpha}}{\left(\varepsilon \omega K_{1}^{\alpha}+K_{2}^{\alpha}\right)^{3}}\left((\alpha-1) K_{1}^{\alpha-2} K_{2}^{\alpha}-\varepsilon \omega K_{1}^{2 \alpha-2}\right)
$$

which is always negative. A similar exercise for player 2 yields the same outcome.

Part (ii): as shown in (14).

Part (iii): Suppose that $\bar{K}_{i}=\frac{\alpha \theta^{1-\alpha}}{r_{i}\left(\theta^{1-\alpha}+1\right)^{2}} S$ for $i \in\{1,2\}$ as derived in the text.

$$
\begin{aligned}
\frac{\partial \bar{K}_{i}}{\partial \theta}=\frac{\alpha(1-\alpha) S}{r_{i} \theta^{\alpha}}\left(\frac{1}{\left(\theta^{1-\alpha}+1\right)^{2}}-\frac{2 \theta^{1-\alpha}}{\left(\theta^{1-\alpha}+1\right)^{3}}\right) & >0 \\
\frac{1-\theta^{1-\alpha}}{\left(\theta^{1-\alpha}+1\right)^{3}} & >0 \\
1 & >\theta
\end{aligned}
$$


Therefore, both $\frac{\partial \bar{K}_{1}}{\partial \theta} \gtreqless 0$ and $\frac{\partial \bar{K}_{2}}{\partial \theta} \gtreqless 0$ as $\theta \lesseqgtr 1$.

\section{Proof of Proposition 3:}

Parts (i) and (ii) follow directly from equilibrium expressions given that $\alpha<1$ and $\theta$ may be greater than 1 .

Part (iii): Suppose $\alpha \in(0,1)$, and $\theta>0$. Consider the difference in equilibrium payoffs for player 1 .

$$
\frac{\theta^{2}(\theta+1-2 \alpha)}{(\theta+1)^{3}} S-\frac{\theta^{1-\alpha}\left(\theta^{1-\alpha}+1-\alpha\right)}{\left(\theta^{1-\alpha}+1\right)^{2}} S
$$

after some algebra we have:

$$
\begin{aligned}
& \frac{S \theta}{(\theta+1)^{3}\left(\theta+\theta^{\alpha}\right)^{2}}\left(\left(\theta^{2}+(1-2 \alpha) \theta\right)\left(\theta+\theta^{\alpha}\right)^{2}+\left((\alpha-1) \theta^{\alpha}-\theta\right)(\theta+1)^{3}\right) \\
& \frac{S \theta}{(\theta+1)^{3}\left(\theta+\theta^{\alpha}\right)^{2}}\left((\alpha+1) \theta^{\alpha+3}+\theta^{2 \alpha+2}-(2+2 \alpha) \theta^{3}-(1+\alpha) \theta^{\alpha+2}\right. \\
& \left.-(2 \alpha-1) \theta^{2 \alpha+1}-(3-3 \alpha) \theta^{\alpha+1}-(1-\alpha) \theta^{\alpha}-3 \theta^{2}-\theta\right)
\end{aligned}
$$

which is always positive for sufficiently high $\theta$ values since the first two terms will dominate the remaining negative terms. The exact threshold at which this difference in payoffs becomes positive does not have a closed form solution; however, it can be easily characterized using numerical methods and graphs as shown in the main text.

A similar exercise can be shown for the difference in payoffs for player 2, only there we must have $\theta$ sufficiently small to guarantee positive sign. It is a trivial demonstration and omitted for brevity.

Therefore, player 1 (2) may prefer Conflict to Bargaining for a given $\alpha$ and sufficiently high (low) $\theta$.

Part (iv): Suppose $\alpha \in(0,1)$, and $\theta>0$. Consider the difference in total equilibrium payoffs, that is $\left(V_{1}^{C *}+V_{2}^{C *}\right)-\left(\bar{V}_{1}^{B}+\bar{V}_{2}^{B}\right)$.

$$
\frac{\theta^{2}(\theta+1-2 \alpha)+\theta(1-2 \alpha)+1}{(\theta+1)^{3}} S-\frac{\theta^{2-2 \alpha}+2 \theta^{1-\alpha}(1-\alpha)+1}{\left(\theta^{1-\alpha}+1\right)^{2}} S
$$

after some algebra we have:

$$
\begin{aligned}
& \frac{S \theta}{(\theta+1)^{3}\left(\theta+\theta^{\alpha}\right)^{2}}\left(2 \alpha \theta^{\alpha+3}+2 \alpha \theta^{\alpha}-(2+2 \alpha) \theta^{3}-(4-2 \alpha) \theta^{\alpha+2}-\right. \\
& \left.(2+2 \alpha) \theta^{2 \alpha+1}-(2+2 \alpha) \theta^{2}-(4-2 \alpha) \theta^{\alpha+1}-(2+2 \alpha) \theta^{2 \alpha}\right)
\end{aligned}
$$


which is always positive for sufficiently high $\theta$ values since the first term will dominate the remaining negative terms. Similarly, it is always positive for sufficiently low $\theta$ values since the fractional exponent in the second term will dominate. The exact thresholds at which this difference in total payoffs becomes positive do not have closed form solutions; however, it can be easily characterized using numerical methods and graphs as shown in the main text.

Therefore, total equilibrium payoffs under Bargaining can be lower than under Conflict.

\section{Solution to the ultimatum bargaining extension.}

Suppose player 1 is the proposer. To accomplish equilibrium settlement, she must propose share $x$ to herself and $1-x$ to player 2 such that player 2 is indifferent between settlement and conflict. That is, $V_{2}^{*}\left(K_{1}, K_{2}\right)=$ $V_{2}^{B}\left(K_{1}, K_{2}\right)$. Hence,

$$
\begin{aligned}
\frac{K_{2}^{\alpha}}{\varepsilon \omega K_{1}^{\alpha}+K_{2}^{\alpha}} S-r_{2} K_{2}-w_{2} \frac{\varepsilon K_{1}^{\alpha} K_{2}^{\alpha}}{w_{1}\left(\varepsilon \omega K_{1}^{\alpha}+K_{2}^{\alpha}\right)^{2}} S & =(1-x) S-r_{2} K_{2} \\
1-x\left(K_{1}, K_{2}\right) & =\frac{K_{2}^{2 \alpha}}{\left(\varepsilon \omega K_{1}^{\alpha}+K_{2}^{\alpha}\right)^{2}}
\end{aligned}
$$

Any offer less than this is rejected and the outcome is conflict. Optimal upfront investments in this case are the same as before. Settlement investments, however, must be reanalyzed since bargaining is no longer symmetric and simultaneous.

Player 2 thus chooses $K_{2}$ to maximize her payoff given the above expression, and Player 1 chooses $K_{1}$ to maximize

$$
x\left(K_{1}, K_{2}\right)=\frac{\varepsilon^{2} \omega^{2} K_{1}^{2 \alpha}+2 \varepsilon \omega K_{1}^{\alpha} K_{2}^{\alpha}}{\left(\varepsilon \omega K_{1}^{\alpha}+K_{2}^{\alpha}\right)^{2}}
$$

giving us first order conditions

$$
K_{1}^{\alpha-1} K_{2}^{2 \alpha}=\frac{r_{1}\left(\varepsilon \omega K_{1}^{\alpha}+K_{2}^{\alpha}\right)^{3}}{2 \alpha \varepsilon \omega S} \quad \text { and } \quad K_{1}^{\alpha} K_{2}^{2 \alpha-1}=\frac{r_{2}\left(\varepsilon \omega K_{1}^{\alpha}+K_{2}^{\alpha}\right)^{3}}{2 \alpha \varepsilon \omega S}
$$

which yield the same relationship as before, $\bar{K}_{1}=\rho \bar{K}_{2}$, but with somewhat different equilibrium expressions

$$
\bar{K}_{1}=\frac{2 \alpha \theta^{1-\alpha}}{r_{1}\left(\theta^{1-\alpha}+1\right)^{3}} S \quad \text { and } \quad \bar{K}_{2}=\frac{2 \alpha \theta^{1-\alpha}}{r_{2}\left(\theta^{1-\alpha}+1\right)^{3}} S
$$


leading us to

$$
\begin{gathered}
\bar{x}_{1}=\frac{\theta^{1-\alpha}\left(\theta^{1-\alpha}+2\right)}{\left(\theta^{1-\alpha}+1\right)^{2}} \\
\bar{V}_{1}^{B}=\frac{\theta^{1-\alpha}\left(\theta^{2-2 \alpha}+3 \theta^{1-\alpha}+(2-2 \alpha)\right)}{\left(\theta^{1-\alpha}+1\right)^{3}} S \\
{\overline{V_{2}}}^{B}=\frac{\theta^{1-\alpha}(1-2 \alpha)+1}{\left(\theta^{1-\alpha}+1\right)^{3}} S
\end{gathered}
$$

Suppose instead that player 2 is the proposer. A similar exercise yields the following equilibrium expressions

$$
\begin{gathered}
\bar{K}_{1}=\frac{2 \alpha \theta^{2-2 \alpha}}{r_{1}\left(\theta^{1-\alpha}+1\right)^{3}} S \quad \text { and } \quad \bar{K}_{2}=\frac{2 \alpha \theta^{2-2 \alpha}}{r_{2}\left(\theta^{1-\alpha}+1\right)^{3}} S \\
\overline{x_{1}}=\frac{\theta^{2-2 \alpha}}{\left(\theta^{1-\alpha}+1\right)^{2}} \\
\bar{V}_{1}^{B}=\frac{\theta^{3-3 \alpha}+\theta^{2-2 \alpha}(1-2 \alpha)}{\left(\theta^{1-\alpha}+1\right)^{3}} S \\
\bar{V}_{2}^{B}=\frac{\theta^{2-2 \alpha}(2-2 \alpha)+2 \theta^{1-\alpha}+1}{\left(\theta^{1-\alpha}+1\right)^{3}} S
\end{gathered}
$$

Therefore the proposer enjoys an additional $\frac{2 \theta^{1-\alpha}}{\left(\theta^{1-\alpha}+1\right)^{2}}$ fraction of the prize. 